\title{
A Durable Livestock Exclosure for Herbage Production and Utilization Sampling
}

\section{R.T. HINNANT AND M.M. KOTHMANN}

Movable livestock exclosures, or cages, are used to protect areas from grazing. These areas may be paired with adjacent unprotected areas and both clipped at intervals to determine forage production and utilization. Two similar plots are located and one is randomly selected to be caged. Detailed accounts of the method and usefulness of the paired plot technique are presented in Brown (1954) and NAS-NRC (1962).

Forage researchers have designed and built a wide variety of cages to satisfy different requirements for size, configuration, convenience of moving, and cost. Cages can assume any apperance or shape; however, Brown (1954) lists several requirements which should be met: (1) the exclosure should be larger than the area to be clipped, (2) the roof should be of wider-meshed wire than that of the sides, or employ roofless exclosures, and (3) they should be easily stored, transported, and moved. Cages should be of adequate height to protect the vegetation fully from grazing animals. They should be sturdy enough to withstand occasional rubbing or bumping by curious livestock. Cages which are easily toppled result in missing data and repairs which increase data collection costs. Popular designs are cubed (Brown 1954, Frischknecht and Conrad 1965, Finlez 1951), teepee-shaped (NAS-NRC 1962), pyramidal (Frischknecht and Conrad 1965, Frischknecht et al. 1969), quonset-shaped (Cowlishaw 1951), electrically charged rectangular-shaped (Prendergast and Brady 1955), and cylindrical (C.J. Scifres, personal communication). Cages have traditionally been designed with metal or wood frames covered with wire mesh, or free-standing square or cylindrical wire mesh anchored to the ground with iron stakes.

The initial cost of cages made from light $>10 \mathrm{ga})$ wire mesh material is low. However, these cages are easily knocked over and damaged by cattle, which results in increased maintenance costs. The cost associated with loss of data from cages which do not exclude cattle is not easily defined but is a major factor which must be considered.

Frischknecht and Conrad (1965) described a $1.524 \mathrm{~m} \mathrm{(5 \textrm {ft } )}$ square welded wire cage ( 10 ga wire) which worked best to protect vegetation from sheep and deer. Their square collapsible cages were unsatisfactory for use with cattle due to damage by rubbing. They found that pyramidal cages located on treeless ranges for short grazing periods were not molested during the spring. Pyramidal cages were damaged as bulls were added to the herd, and in low swale areas where cattle congregated. Pyramidal cages are not suitable for tall grass ranges, and the bottom wires are damaged by trampling. Small diameter wire is easily damaged by rubbing, especially from horned animals.

A sturdy, reliable, and long-lasting cage has been developed and in use for 4 years on Coastal Prairie range in Texas. Each cage is made from one readily available 1.32 by $4.877 \mathrm{~m}(52 \mathrm{in}$. by $16 \mathrm{ft})$ galvanized cattle panel $[.635 \mathrm{~cm}(1 / 4 \mathrm{in}$.) steel] and two $1.38 \mathrm{~m}(6 \mathrm{ft})$ steel "T" posts (Fig. 1). Mesh configuration can be of 10.16 by $15.24 \mathrm{~cm}$ ( 4 by 6 in.) rectangles (cattle panel), or of varying sizes (combination panel). The combination panel is not recommended since some of the mesh sizes are large enough for a calf to insert its head. The 10.16 by $15.24 \mathrm{~cm}$ ( 4 by 6 in.) rectangular mesh is easier

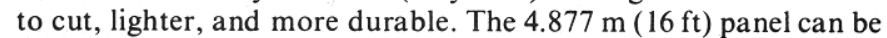
cut into four, $1.219 \mathrm{~m}$ (4-ft) lengths by bolt cutters, hacksaw, or oxy-acetylene torch. The oxy-acetylene cut is more desirable since it leaves rounded instead of sharp edges. The four 1.32 by $4.877 \mathrm{~m}$

Authors are research associate and professor, Department of Range Science, Texas Agricultural Experiment Station, Texas A\&M University, College Station 77843.

Manuscript received May 16, 1980.

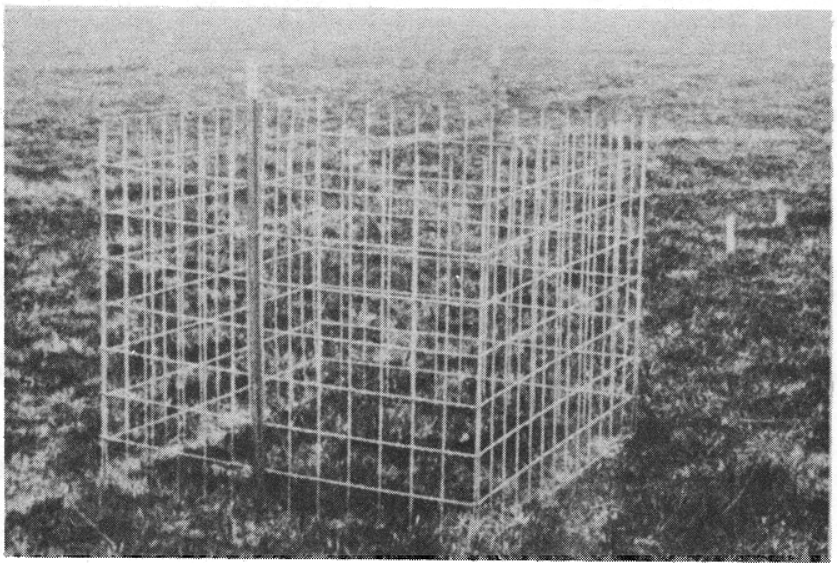

Fig. 1. Portable livestock exclosures anchored by two $6 \mathrm{ft}$ steel "T" posts. Paired plot in background is marked by two 18-inch wooden stakes. Area was burned I week prior to being photographed with cages and wood takes in place.

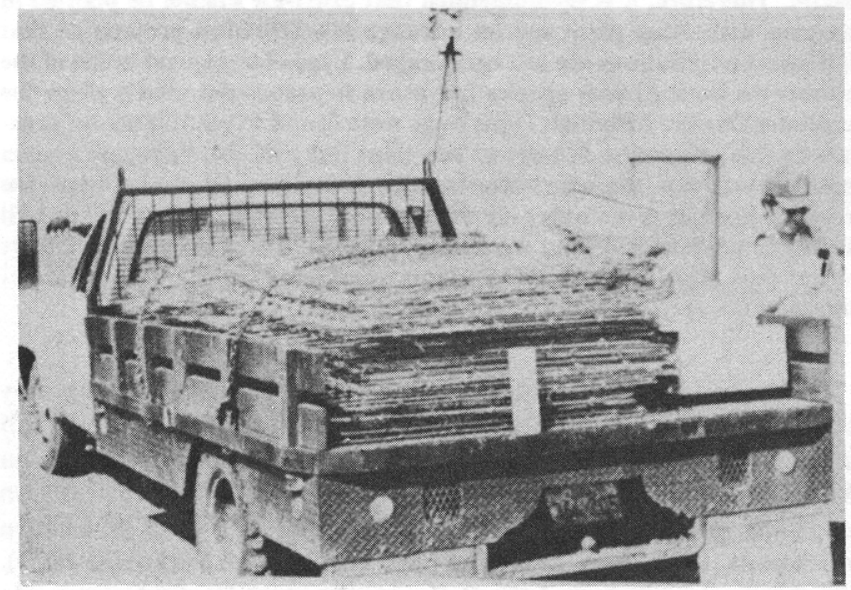

Fig. 2. These cages are easily collapsed and transported. The truck is loaded with 32 cages, 64 steel " $T$ " posts, and other equipment for clipping.

( 52 in. by $4 \mathrm{ft}$ ) sections are then loosely tied with galvanized wire so that the cages can be folded into a 1.32 by $2.4328 \mathrm{~m}(52 \mathrm{in}$. by $8 \mathrm{ft})$ rectangular shape for carrying by one person, for storage and transporting (Fig. 2). The cages are then secured by two $1.83-\mathrm{m}(6$ ft) steel " $T$ " posts driven into the ground and tied to the cage with wire: A cage can be moved to a new location and set up within 5 minutes. The material cost of the completed cage is currently under $\$ 25$. The cage protects an area adequate to accommodate plots of 1 $\mathrm{m}^{2}$ leaving approximately $15.24 \mathrm{~cm}(6$ in.) from the plot frame to the cage sides to minimize the border effect.

Cages constructed from cattle panels and secured by two steel posts have several advantages over the cages described by Frischknecht and Conrad (1965). These cages are (1) not damaged by rubbing or trampling, (2) maintenance free, and (3) more reliable for protecting the vegetation. Construction of these cages is from stronger, more durable material $(6.35 \mathrm{~mm}$ wire), and practically immovable when anchored by two steel posts.

These cages have been rust-free even though the study location is only 12 miles from the coast. The galvanized panels will provide 
years of maintenance-free service reducing the long-term costs of cages. These cages have been used for over 4 years in 141.65-ha pastures with as many as 400 Santa Gertrudes (horned and polled) cows and bulls. Since there are no trees in these pastures, livestock frequently use the cages for rubbing and scratching; however, not one has been damaged, or failed to protect the $1 \mathrm{~m}^{2}$ necessary for the plot frame.

\section{Literature Cited}

Brown, Dorothy. 1954. Methods of Surveying and Measuring Vegetation. Commonwealth Agricultural Bureaux. Farnham Royal Bucks. England.
Cowlishaw, S.J. 1951. The effect of sampling cages on the yields of herbage. Brit. Grassl. Soc. J. 6:179-184.

Fenley, J.M. 1951. A one-man portable livestock exclosure. J. Range Manage. 4:112-113.

Frischknecht, N.C., and P.W. Conrad. 1965. Adaptable, transportable utilization cages. J. Range Manage. 18:33-34.

Frischknecht, N.C., P.W. Conrad, and P.E. Hansen. 1969. Improved folding utilization cages. J. Range Manage. 23:215-216.

NAS-NRC. 1962. Basic problems and techniques in range research. National Academy of Sciences-National Research Council. Washington, D.C. 341 p.

Prendergast, J.J., and J.J. Bradley. 1955. Improved movable cage for use in grassland research. Brit. Grassl. Soc. J. 10:189-190. 